\title{
Hydrodynamic control of gas-exchange velocity in small streams
}

\author{
Andreas Lorke ${ }^{1 *}$, Pascal Bodmer ${ }^{1}$, Kaan Koca ${ }^{1}$ and Christian Noss ${ }^{1}$ \\ ${ }^{1}$ Institute for Environmental Sciences, University of Koblenz-Landau, Fortstr. 7, 76829 Landau, \\ Germany \\ * Corresponding author: lorke@uni-landau.de
}

\section{Key findings:}

- For smooth and rippled flows with isotropic turbulence, gas exchange velocities follow a universal scaling with turbulent dissipation

- In rough flows with anisotropic turbulence, gas exchange velocities are lower than predicted from dissipation rates

- Quantitative assessment of surface flow types may facilitate improved mapping of gas exchange velocities at larger spatial scales

\begin{abstract}
Gas exchange is a critical component of any biogeochemical mass balance model of dissolved gases in aquatic systems, yet the magnitude and drivers of spatial and temporal variations of airwater exchange rates in shallow streams are poorly understood. We investigated the relationships between gas exchange velocity of carbon dioxide and methane and flow hydraulics at different sections along a third order stream in Southwest Germany. To cover a wide range of different flow conditions, the sections were selected based on visual categorization of the dominant surface flow type. We found that in smooth and rippled flows, gas exchange velocities followed a universal dependence on turbulent dissipation rates predicted by the small-eddy and surface renewal models. For these surface flow types, the scaling applied to both, bulk-scale dissipation rates estimated from flow geometry and dissipation rates estimated from turbulence measurements. Turbulence was strongly anisotropic under rough flow conditions and gas exchange velocities were lower than predicted from measured dissipation rates. Nevertheless, near-surface turbulence and gas exchange velocities differed among surface flow type categories, indicating that quantitative assessment and mapping of surface flow type may facilitate improved parameterizations of gas exchange velocities at larger spatial scales. We further describe a novel instrument facilitating an objective assessment of surface flow by measuring the acceleration of a small floating sphere drifting freely on the water surface. In combination, our findings may open a new road for understanding, measuring and predicting spatial and temporal variability of gas exchange in streams.
\end{abstract}




\section{Introduction}

Gas exchange at water surfaces is an important component of biogeochemical fluxes in streams and rivers (Mulholland et al. 2001; Aufdenkampe et al. 2011; Long et al. 2015). The diffusive gas exchange across an air-water interface is the product of the partial pressure difference between atmospheric and dissolved gas concentration, water surface area and the gas exchange (or piston) velocity (Jähne and Haußecker 1998). While the dissolved gas concentrations in rivers and streams are controlled by inputs, biogeochemical transformations and outputs (Hotchkiss et al. 2015), the gas exchange velocity is mainly controlled by turbulent mixing at the water side of the air-water interface (Jähne and Haußecker 1998). The flow-dependence of the exchange velocity is a major driver of large spatial and temporal variability of gas exchange rates of rivers and streams at the reach scale, as well as at catchment scales (Alin et al. 2011; Wallin et al. 2011; Schelker et al. 2016).

With turbulence near the air-water interface providing the major physical control of gas exchange velocities, their observed variability in streams has been empirically related to slope, water current velocity and depth in small streams (Alin et al. 2011; Raymond et al. 2012). In physically-based models, gas exchange velocities have been linked to near-surface turbulence in the small eddy, or diffusive boundary layer approach (Lorke and Peeters 2006), or the surface renewal model (Lamont and Scott 1970). Recently is has been demonstrated that both conceptual models generate a universal scaling for the air-water gas transfer velocity $k$ as a function of the dissipation rate of turbulent kinetic energy $\varepsilon$ (Katul and Liu 2017):

$$
k=\alpha(\varepsilon v)^{1 / 4} S c^{-n}
$$

where $v$ is the kinematic viscosity of water, $S c$ is the Schmidt number (i.e. the ratio of kinematic viscosity and the diffusion coefficient of the corresponding gas in water) and $\alpha$ is a scaling coefficient. The functional relationship between the gas exchange velocity and energy dissipation rates in Eq. 1 has been validated in field measurements in wind-driven systems, including the marine environment (Zappa et al. 2007; Esters et al. 2017), coastal areas (Tokoro et al. 2008; Gålfalk et al. 2013), and lakes (Vachon et al. 2010; Wang et al. 2015). Among these studies, relatively large variations of the values for the scaling coefficient $\alpha$ were observed (Tokoro et al. 2008; Wang et al. 2015; Esters et al. 2017). Because in wind-driven boundary layers, dissipation rates of turbulent kinetic energy decrease reciprocally with distance from the water surface, $\alpha$ can be expected to depend on the measurements depth of $\varepsilon$ in these systems (Lorke and Peeters 2006; Esters et al. 2017). No field-based validation of Eq. 1 is available for streams and other aquatic system where turbulence is predominantly generated by gravity. Laboratory investigations in smooth and rough channels, however, supported this relationship (Moog and Jirka 1999a; Moog and Jirka 1999b).

Although a relationship between turbulent energy dissipation and gas exchange can provide mechanistic understanding of spatial and temporal variations of gas exchange rates in streams, its application in larger-scale assessments is limited by the capabilities to measure and to predict near- 
surface turbulence at the catchment scale. As an alternative or an addition to using empirical relationships with slope, flow velocity and depth, Raymond et al. (2012) suggested to use potential proxies that can be used to probe the effect of boundary conditions on turbulence near the air-water interface. Such proxies have been developed to characterize physical biotopes for ecological assessments of water quality in streams and rivers (Kemp et al. 2000; Clifford et al. 2006). Among these concepts, visual surveys of different surface flow types (e.g., smooth boundary turbulence, rippled flow, unbroken and broken standing waves) have become an established method (Newson and Newson 2000). While applications of these proxies have mainly been limited to the characterization of benthic habitats in streams, their suitability for characterizing gas exchange velocities by rapid surveys remained unexplored.

Here we investigate the relationship between near-surface turbulence and gas exchange velocities in a small stream. Based on field measurements of turbulence and gas exchange velocities in streams featuring different surface flow types, we test to what extent exchange velocities in small streams follow the same universal dependence on turbulence dissipation rates as observed for wind-driven systems (Eq. 1). We further link gas exchange and turbulence to visual appearance of stream flow (surface flow type) and to bulk parameterizations of energy dissipation rates. Finally, we test new instrumentation for rapid and objective section-scale assessments of surface flow type and gas exchange velocity in streams. Parts of these analyses were presented at the River Flow conference in 2018 (Noss et al. 2018).

\section{Methods}

\subsection{Study sites and sampling overview}

Atmospheric fluxes of $\mathrm{CO}_{2}$ and $\mathrm{CH}_{4}$ along with bulk flow characteristics, turbulence and water surface roughness were measured at four different sections of the Wellbach, a headwater stream (Strahler order 3) located in the Palatinate-Forest in Southwest Germany. The Wellbach is classified as a small, fine-substrate dominated, siliceous highland river (Dahm et al. 2014). To cover a wide range of different flow conditions, four different measurement sections were selected based on the dominant surface flow type, which was visually assessed following the categorization of Newson and Newson (2000): smooth boundary turbulence (SBT), rippled flow (RIP), unbroken standing wave (USW) and broken standing wave (BSW) (Fig. 1a-d). The riverbed at the SBT section consisted of sand with ripples. Only small turbulent flow cells of this glide flow disturbed the predominantly smooth water surface. The RIP section was a rather narrow and deep run flow with downstream propagating ripples at the water surface. Unbroken standing waves were present in a straight riffle flow section with gravel and cobble riverbed. The broken standing waves were associated with surging flows downstream of protruding boulders, i.e. local cascades.

At each of the approximately $15 \mathrm{~m}$ long sections, measurements were performed at two to four sampling spots with characteristic surface flow types. All measurements were made from an instrument frame (tripod), which was deployed in the stream between 2 and 15 December 2016. A 
picture of the instrumented tripod is provided in the supplementary information (Fig. S1). Atmospheric fluxes were measured using static (flying) chambers. Subsequently, the flow and turbulence below the location of chamber deployment were measured using two different instruments: an acoustic Doppler velocimeter (ADV) measured the three-dimensional flow velocity at one particular location, while the spatial distribution of two-dimensional (longitudinal and vertical) flow fields was measured by particle image velocimetry (PIV). To maximize data quality of the PIV flow measurements, all sampling was conducted during darkness.

At the BSW section, gas fluxes were measured at two spots (BSW 1 and BSW 2) but flow and turbulence measurements were not possible because of large boulders and shallow water depth, which impeded the deployment and application of ADV and PIV. At the remaining sections, flow and turbulence was measured at three spots (SBT 1-3, RIP 1-3, USW 2-4), while gas fluxes were measured at one additional spot (USW 1) and failed at SBT 3 (no significant correlation, see below).
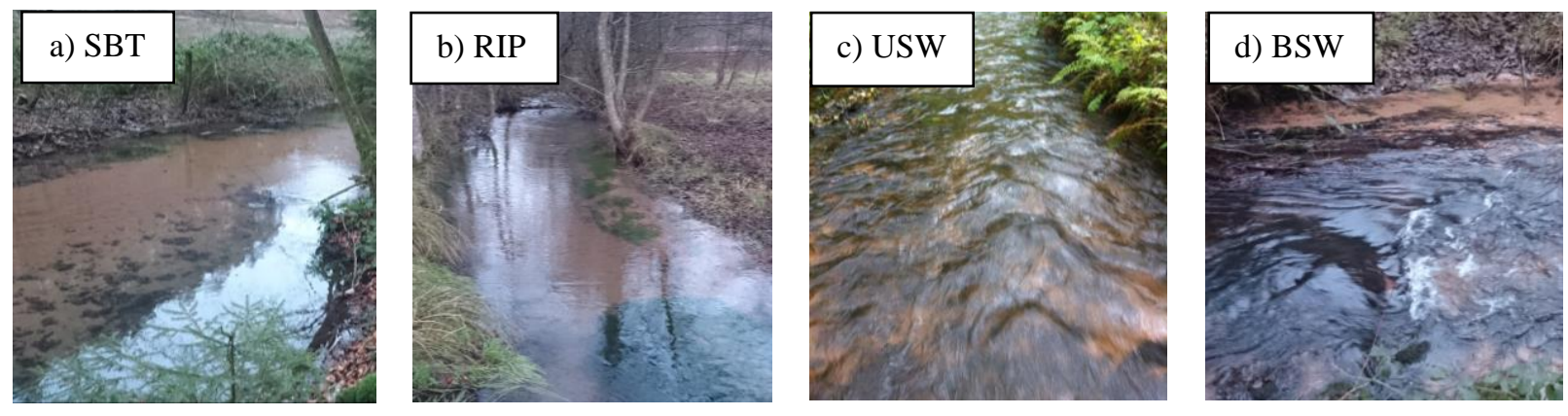

Figure 1: Study sites at the Wellbach featuring different surface flow types: a) Smooth boundary turbulence (SBT), b) rippled flow (RIP), c) unbroken standing wave (USW) and d) broken standing wave (BSW).

\subsection{Bulk characteristics of the stream sections}

At the SBT, RIP and USW sections, mean flow depth $(H)$, stream width $(W)$, water level slope $(S)$ and near-surface flow speed $\left(U_{S}\right)$ were measured with a surveyor's level and an electromagnetic current meter (OTT MF Pro). Flow depth and near-surface flow speed were estimated along the approximately $15 \mathrm{~m}$ long sections as averages over 50 to 55 measurements performed at equidistantly divided cross-sections with 5 measurements in each of them.

Section-scale Froude number $(F r)$ and Reynolds number $(R e)$ were estimated as:

$$
F r=U_{S} / \sqrt{g H} ; R e=U_{S} R_{h} / v
$$

where $g$ is the gravitational acceleration, $R_{h}=H W /(W+2 H)$ is the hydraulic radius.

Following Moog and Jirka (1999a) and Raymond et al. (2012), section-scale energy dissipation rates were estimated using two different approaches. The first approach is based on the assumption that channel drag and corresponding energy dissipation are uniformly distributed over depth. In this case, the energy dissipation rate $\left(\varepsilon_{D}\right)$ corresponds to stream power per unit mass of water and was calculated as: 
Non-peer reviewed preprint submitted to EarthArXiv

$$
\varepsilon_{D}=g S U_{S}
$$

Alternatively, section-scale energy dissipation rates were estimated by assuming a boundarylayer flow, where energy dissipation is governed by bed shear stress. For smooth and smallroughness flows (Moog and Jirka 1999b), the average dissipation rate per unit mass of water $\left(\varepsilon_{S}\right)$ can be estimated from channel geometry and slope as:

$$
\varepsilon_{S}=\left(g R_{h} S\right)^{3 / 2} / H
$$

\subsection{Gas exchange velocity}

Fluxes of $\mathrm{CO}_{2}$ and $\mathrm{CH}_{4}$ at the water-air interface were measured using a static floating chamber (circular chamber at SBT, RIP, USW: 12 L volume, $0.09 \mathrm{~m}^{2}$ bottom area; at BSW: 24 L volume, $0.17 \mathrm{~m}^{2}$ bottom area), which was mounted to the tripod. To avoid the measurement bias caused by inference of the submerged chamber edges with the flow (Lorke et al. 2015), we applied a flying chamber design (Lorke et al. 2015; Rosentreter et al. 2017) in which the chamber edges are not submerged. To seal the chamber headspace from ambient air, a thin $(0.007 \mathrm{~mm})$ plastic foil was used, which adhered to the water surface. In order to avoid any contact of the rigid part of the chamber with the water surface, we placed the chamber at an appropriate distance ( 2 to $5 \mathrm{~cm}$ ) above the water surface. The flying chamber was connected to an Ultraportable Greenhouse Gas Analyzer (UGGA; Los Gatos Research, Inc., USA) via two 4.65-meter-long gas-tight tubes (Tygon E3603), creating a circulating gas loop between the chamber headspace and the UGGA. The flying chamber was placed for ca. 2 min on the water surface (3-4 replicates per spot for RIP, USW and STB; 4-7 replicates per spot for BSW). Fluxes of $\mathrm{CO}_{2}$ and $\mathrm{CH}_{4}$ were obtained from the measured linear increase of $\mathrm{CO}_{2}$ and $\mathrm{CH}_{4}$ in the chamber headspace and calculated according to Bodmer et al. (2016). While the initial linear slope was calculated for time periods ranging between $24 \mathrm{~s}$ to 2.3 min. we only considered significant slopes (ANOVA, $p<0.05$; average $r^{2}$ of all slopes was 0.7).

Partial pressures of $\mathrm{CO}_{2}\left(p \mathrm{CO}_{2}\right)$ and $\mathrm{CH}_{4}\left(p \mathrm{CH}_{4}\right)$ in water samples were measured on-site using the headspace method (one sample before, during and after each spot measurement). The headspace measurements were conducted using the UGGA with closed-loop as described in Alshboul et al. (2016). Furthermore, we measured $p \mathrm{CO}_{2}$ and $p \mathrm{CH}_{4}$ in the atmosphere at each site with the UGGA. Gas transfer (piston) velocities $\left(k\right.$ in $\left.\mathrm{m} \mathrm{d}^{-1}\right)$ were estimated from measured fluxes $\left(F\right.$ in mol m${ }^{-2} \mathrm{~d}^{-}$

${ }^{1}$ ) and respective partial pressures (water and atmosphere) of $\mathrm{CO}_{2}$ and $\mathrm{CH}_{4}(\mu \mathrm{atm})$ :

$$
k=\frac{F}{K_{H}(\Delta p C)},
$$

where $K_{H}$ is Henry's constant $\left(\mathrm{mol} \mathrm{L}^{-1} \mathrm{~atm}^{-1}\right.$ ) adjusted for in-situ water temperature (Goldenfum 2010) and $\triangle p C$ is the difference of the partial pressure of $\mathrm{CO}_{2}$ or $\mathrm{CH}_{4}$ in water and in the atmosphere. We standardized $k$ of $\mathrm{CO}_{2}$ and $\mathrm{CH}_{4}$ at in-situ temperature to $k_{600}$, i.e. $k$ for a Schmidt number $(S c)$ of 600 , according to Jähne et al. (1987):

$$
k_{600}=k\left(\frac{600}{S c}\right)^{-0.5} \text {, }
$$


where $k$ at in-situ temperature was calculated using Eq. 5 for $\mathrm{CO}_{2}$ and $\mathrm{CH}_{4}$, respectively, and $S c$ is the corresponding Schmidt number (calculated according to Wanninkhof, 1992). We chose an exponent of -0.5 , which showed best agreement in the compilation of gas exchange velocities measured in different aquatic systems (Zappa et al. 2007).

Visual observations during the measurements suggested that ebullition did not occur at the sampled stream sections.

\subsection{Flow velocity and turbulence}

Flow velocity and turbulence measurements below the chamber were performed after the flux measurements by PIV and by ADV. The upper boundary of the field of view (FOV) of the PIV was $2 \mathrm{~cm}$ below the lowest elevation of the water surface. The ADV sampling volume was located $14 \mathrm{~cm}$ below the water surface and $23 \mathrm{~cm}$ from the left end of the FOV.

The ADV (Vector, Nortek AS) was mounted in parallel to the mean flow direction, i.e. the instrument's $z$-axis, which provides most accurate velocity measurements, was aligned with the longitudinal flow direction while its $x$-axis pointed vertically upward. Measurements were conducted for at least 3 min with a sampling frequency of $64 \mathrm{~Hz}$. The velocity range was set to 1 $\mathrm{m} \mathrm{s}^{-1}$ for measurements at SBT, $2 \mathrm{~m} \mathrm{~s}^{-1}$ at RIP and $7 \mathrm{~m} \mathrm{~s}^{-1}$ at USW. We used a pulse transmit length of $2 \mathrm{~mm}$ and a $16 \mathrm{~mm}$ high sampling volume for the measurements at the USW spots, and $4 \mathrm{~mm}$ transmit length and $14.9 \mathrm{~mm}$ sampling volume height at all other sites.

The custom-made PIV-system consisted of a digital camera (Sony RX100IV) and a green continuous wave laser (Hercules-225, Laserglow) with a Powell-lens to expand the laser beam to a planar light sheet with an opening angle of $60^{\circ}$ (see, e.g., Stamhuis (2006) for an overview of PIV measurement and analysis principles). All PIV components were placed under water with the laser located downstream of the sampling spot and the camera was arranged perpendicular to the light sheet at a lateral distance of $37 \mathrm{~cm}$ (suppl. Figure S2). Natural suspended particles were illuminated by the laser and videos of the $416 \mathrm{~mm}$ wide and $224 \mathrm{~mm}$ high FOV were recorded with a frame rate of $120 \mathrm{~Hz}$ for at least $3 \mathrm{~min}$ at each spot. Instantaneous two-dimensional velocity vectors at a spatial resolution of $8 \mathrm{~mm} \times 8 \mathrm{~mm}$ were calculated using a three-step adaptive correlation algorithm with final interrogation areas of $64 \times 64$ pixel and $50 \%$ overlap with the software DynamicStudio V (Dantec Dynamics). In the adaptive correlation procedure initial velocity vectors are estimated in large interrogation areas $(256 \times 256$ pixel $)$ and subsequently refined in smaller sized interrogation areas. Spurious velocity vectors were identified by peak validation and replaced by a moving average spanning 7 × 7 interrogation areas. 22-29\% of the velocity vectors were substituted during the iterative processing of the adaptive correlation at the SBT sites, while 35-59 \% and 78-82 \% of the vectors were substituted at the RIP and USW sites, respectively.

Time series of longitudinal $(u(t))$ and vertical $(w(t))$ flow velocities measured by the ADV and in each interrogation area of the PIV were decomposed into mean $(\bar{u}, \bar{w})$ and temporarily 
fluctuating $\left(u^{\prime}(t), w^{\prime}(t)\right)$ components by subtracting temporal mean values from the measured instantaneous velocities. Spectral analysis of velocity fluctuations revealed that the measurements were dominated by noise at frequencies $>10 \mathrm{~Hz}$ for both PIV and the longitudinal ADV velocity components, and at frequencies $>3 \mathrm{~Hz}$ for the vertical ADV velocity. To exclude the noise from subsequent statistical analysis, zero-phase low-pass filter $\left(12^{\text {th }}\right.$ order Butterworth) with corresponding cut-off frequencies were applied to the velocity time series, after de-spiking using the method described in Goring and Nikora (2002).

For the low-pass filtered velocities from both instruments, we estimated root mean square values of velocity fluctuations $\left(u_{r m s}, w_{r m s}\right)$ and turbulent kinetic energy $(T K E)$ as:

$$
T K E=\frac{1}{2}\left(\overline{u^{\prime 2}}+2 \overline{w^{\prime 2}}\right)=\frac{1}{2}\left(u_{r m s}^{2}+2 w_{r m s}^{2}\right)
$$

where the overbar denotes temporal averaging over the entire deployment length. The spatial structure of the velocity fluctuations was characterized using the vorticity $(\omega)$ of the twodimensional flow field observed by PIV:

$$
\omega=\frac{\partial u \prime}{\partial x}-\frac{\partial w \prime}{\partial z}
$$

The vorticity scales with the angular velocities of turbulent eddies in the planar FOV.

Power-spectral density $\left(P_{u}, P_{w}\right)$ of velocity fluctuations was estimated from unfiltered velocity time series using Welch's method (Emery and Thomson 2004). Frequency spectra were converted to wavenumber spectra using Taylor's hypothesis of frozen turbulence $(\kappa=f / \bar{u}$, frequencies $(f)$ and wavenumbers $(\kappa)$ are reported as cycles per second and per meter, respectively).

Dissipation rates of turbulent kinetic energy $\left(\varepsilon_{u}, \varepsilon_{w}\right)$ were estimated using the inertial dissipation technique (Bluteau et al. 2011). A constant slope of $\kappa^{-5 / 3}$ was fitted to the inertial subrange in measured wavenumber spectra to match the theoretical spectrum:

$$
P(k)=\bar{u} P(f / \bar{u})=2 \pi A \varepsilon^{2 / 3}(2 \pi \kappa)^{-5 / 3}
$$

We used $A=0.49$ for the spectrum of the longitudinal velocity component $\left(P_{u}\right)$ and $A=0.65$ for the spectrum of the vertical component $\left(P_{w}\right)$ (Bluteau et al. 2011).

The flow velocities and derived quantities describing mean flow and turbulence measured by ADV and PIV agreed reasonably well at all sampling sites. A detailed comparison of the results from both instruments is provided as supplemental information (Figures S2-S4). In the following, we report PIV observations only.

\subsection{Drifter}

Water surface roughness was quantified at each section using a novel instrument consisting of a small (28 $\mathrm{mm}$ diameter) floating sphere, which measured acceleration while drifting freely on the stream surface. The hardware of the battery-powered drifter consisted of a 9-axis orientation sensor (Bosch BNO55) and electronic periphery including memory and a computer interface for data 
download. Only raw acceleration readings of the accelerometer were used for further analyses, because drifter orientation, which could be estimated by sensor fusion with a compass and gyroscope data, failed in the present drifter application. Three-dimensional acceleration vectors were sampled at $50 \mathrm{~Hz}$ and with a resolution of $0.0024 \mathrm{~m} \mathrm{~s}^{-2}$.

The standard deviation of acceleration measured by the drifter is related to buoyancy-driven vertical oscillations of the drifter at the water surface and can be expected to be related to surface roughness and predominantly horizontal velocity gradients. Standard deviations of the acceleration magnitude were averaged over repeated runs at the same section, where a run corresponds to the motion of the drifter while floating along the investigated stream section. Between 10 and 28 successful runs of the drifter along the sections (i.e. without contact with the stream banks) were conducted before the flux and turbulence measurements. At the BSW sites (16 runs), only short sequences of drifter acceleration, when it passed the broken surface water of the hydraulic jump, were analyzed, while whole section runs were used to characterize the quasi-uniform surface flow types of SBT (13 runs), RIP (28 runs) and USW (10 runs).

\section{Results}

\subsection{Bulk hydrodynamics}

The largest variability of the measured characteristics among the different surface flow types were observed in energy dissipation rates and water surface slopes, which increased by two to three orders of magnitude from SBT and RIP to USW sections (Table 1). The energy dissipation estimates $\varepsilon_{S}$, which are solely based on stream slope and depth (Eq. 4), were consistently (up to one order of magnitude) smaller and more variable among the surface flow types than $\varepsilon_{D}$, which is based on slope and observed flow speed (Table 1).

The mean flow speed was smallest at the SBT section $\left(0.17 \mathrm{~m} \mathrm{~s}^{-1}\right)$ and nearly five-fold higher at the USW section $\left(0.76 \mathrm{~m} \mathrm{~s}^{-1}\right)$. Similarly, Reynolds numbers increased by a factor of three from SBT $\left(3 \cdot 10^{-4}\right)$ to USW $\left(1 \cdot 10^{-5}\right)$ sections. Froude numbers were smallest $(0.1)$ at SBT and highest $(0.51)$ at USW and were indicating subcritical flow $(F r<1)$ at all sections.

Table 1: General hydraulic characteristics of the stream sections with different surface flow types (SBT; smooth boundary turbulence, RIP: rippled flow, USW: unbroken standing wave): mean flow depth $(H)$, mean stream width $(W)$, water surface slope $(S)$, mean flow speed ( $U_{S}$, arithmetic mean over 50-55 measurements), Froude number $(F r)$, Reynolds number $(R e)$ and energy dissipation rates estimated from uniform channel drag ( $\varepsilon_{D}$, Eq. 3$)$ and from bed shear stress ( $\varepsilon_{S}$, Eq. 4).

\begin{tabular}{c|c|c|c|c|c|c|c|c}
$\begin{array}{c}\text { Surface } \\
\text { flow type }\end{array}$ & $\begin{array}{c}H \\
(\mathrm{~m})\end{array}$ & $\begin{array}{c}W \\
(\mathrm{~m})\end{array}$ & $\begin{array}{c}S \\
(\%)\end{array}$ & $\begin{array}{c}U_{S} \\
\left(\mathrm{~m} \mathrm{~s}^{-1}\right)\end{array}$ & $\begin{array}{c}F r \\
(-)\end{array}$ & $\begin{array}{c}R e \\
(-)\end{array}$ & $\begin{array}{c}\varepsilon_{D} \\
\left(\mathrm{~W} \mathrm{~kg}^{-1}\right)\end{array}$ & $\begin{array}{c}\varepsilon_{S} \\
\left(\mathrm{~W} \mathrm{~kg}^{-1}\right)\end{array}$ \\
\hline SBT & 0.31 & 5.22 & 0.02 & 0.17 & 0.10 & $3.1 \cdot 10^{4}$ & $3.3 \cdot 10^{-4}$ & $4.1 \cdot 10^{-5}$ \\
RIP & 0.40 & 3.59 & 0.04 & 0.30 & 0.15 & $6.5 \cdot 10^{4}$ & $1.2 \cdot 10^{-3}$ & $1.1 \cdot 10^{-4}$ \\
USW & 0.23 & 3.24 & 1.06 & 0.76 & 0.51 & $1.0 \cdot 10^{5}$ & $7.9 \cdot 10^{-2}$ & $1.3 \cdot 10^{-2}$
\end{tabular}




\subsection{Turbulence}

Despite the different mean flow velocity and magnitude of turbulent velocity fluctuations, the flow patterns at SBT and RIP did not differ notably. The patterns consisted of $5-10 \mathrm{~cm}$ sized turbulent eddies of random direction of rotation, which were advected horizontally through the field of view by the mean flow velocity at the SBT and RIP sections (Fig. 2a). There, eddies were carried into the field of view by larger-scale flow structures and remained without notable change in structure, size and speed during their passage. AT USW in contrast, turbulent eddies and flow structures were less persistent and rapidly generated and dissipated within the field of view. Particularly at the most shallow site (USW spot 2, Fig. 2b), turbulent flow structures were frequently being shed from the more stationary, topographically forced, vortices and propagated also vertically towards the water surface.
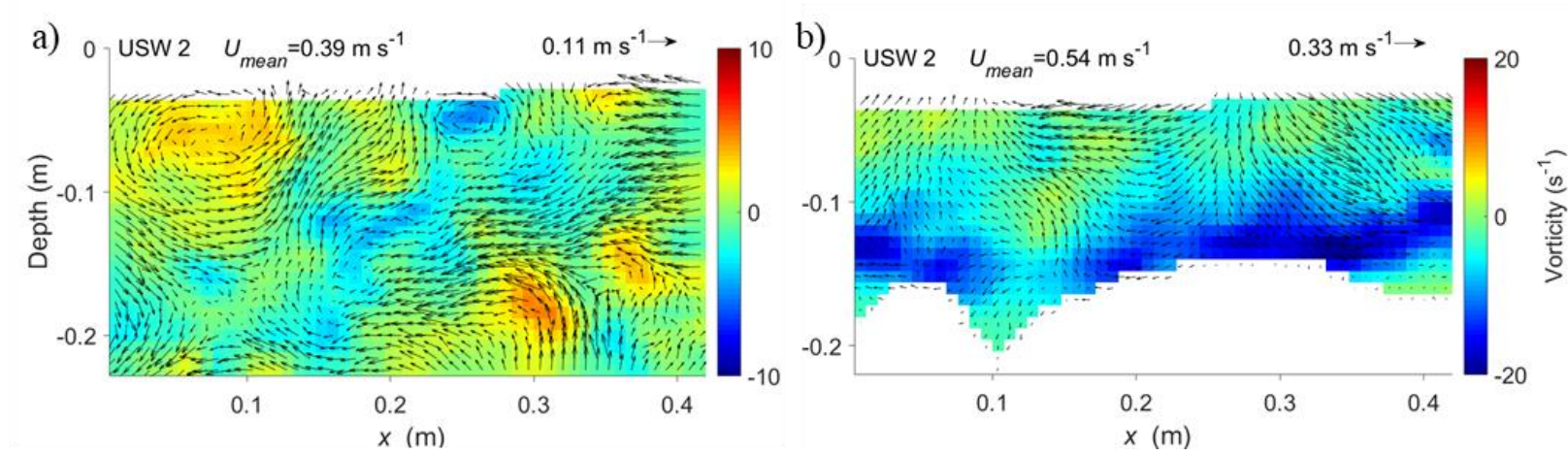

Figure 2: Snapshots of instantaneous turbulent velocity fluctuations for a) smooth boundary turbulence (SBT spot 3) and b) unbroken standing wave (USW spot 2). The vectors show magnitude and direction of turbulent velocity fluctuations (a reference arrow is provided in the top left corner of each panel). The white area at the bottom of b) masks the stream bed. The mean current speed $\left(U_{\text {mean }}\right)$ that has been subtracted from the measured flow velocities is shown in the panel headings. The velocities are overlaid a color image showing the $y$-component of instantaneous vorticity. The vorticity ( $\omega$, Eq. 8) scales with the angular velocity of clockwise (blue color) and counterclockwise (red color) rotating eddies in the planar field of view.

Turbulent kinetic energy increased by about one order of magnitude for the three-fold increase of mean flow velocity from SBT to USW sites (turbulent quantities measured at the individual sampling spots are listed in supplementary information, Table S1). TKE was mainly determined by variance of the longitudinal velocity, which had root-mean-square values nearly twofold those of the vertical component. Spectral analysis of velocity fluctuations revealed that the major contributions to turbulent kinetic energy were associated with spatial scales between flow depth and stream width (Fig. 3). At the SBT and RIP sites longitudinal velocity variance had a pronounced peak at wavenumbers corresponding to stream width, while the vertical velocity variance was maximum for wave numbers corresponding to flow depth at all sections. In SBT and RIP flows, turbulence became most isotropic, i.e. comparable spectral density of longitudinal and vertical velocity variance, for wave numbers exceeding $\kappa_{H}=1 / H$, i.e. for length scales smaller than water depth. An inertial subrange could be observed in both longitudinal and vertical velocity 
fluctuations for wave numbers up to $20-30 \mathrm{~m}^{-1}$ where the spectra flattened towards higher wave numbers due to measurement noise. At the USW sites, turbulence was strongly anisotropic over the observed wave number range (Fig. 3c). At all sites, noise caused a strong increase in spectral density for wavenumber exceeding $\kappa_{\text {noise }}=10 \mathrm{~Hz} / U_{\text {mean }}$, i.e. for frequencies exceeding the $10 \mathrm{~Hz}$ noise limit, which was excluded from all other analysis by low-pass filtering (cf. method section). Noise dominated the spectral velocity variance at spatial scales $<0.03 \mathrm{~m}$ at the low-energetic SBT and $<0.07 \mathrm{~m}$ at the USW sections.

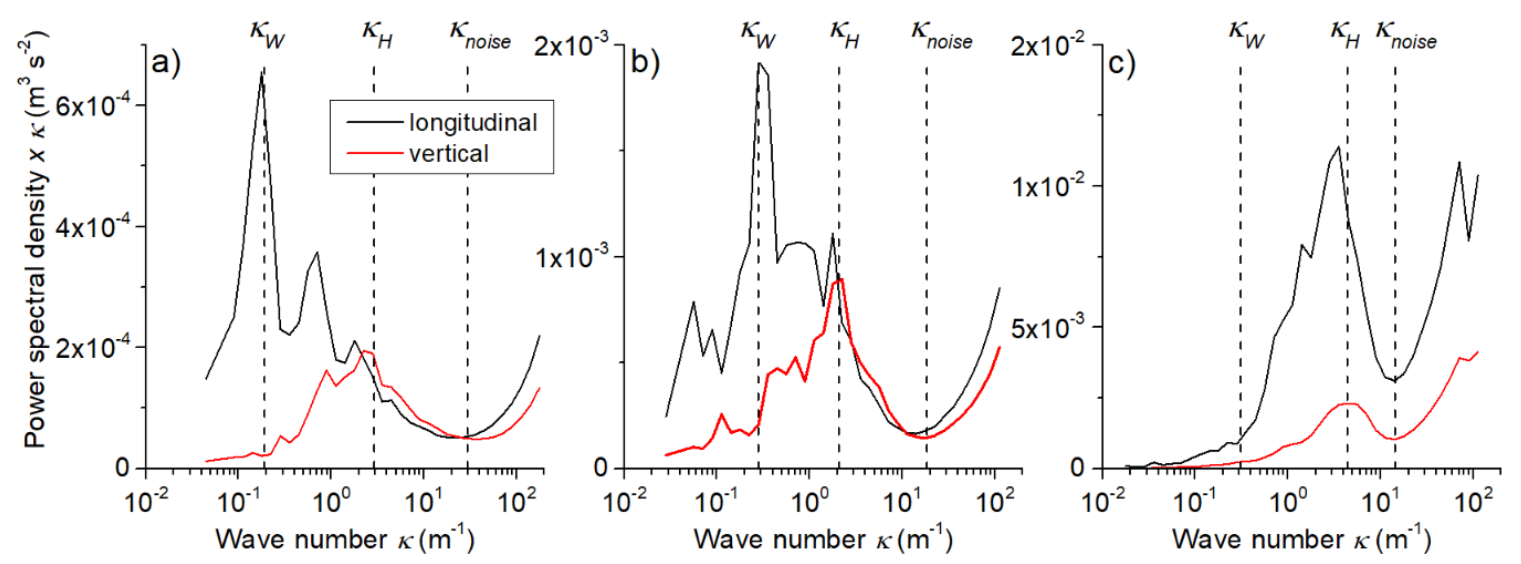

Figure 3: Variance-preserving presentation of power spectral density of velocity fluctuations at a) SBT, b) RIP and c) USW sampling sites. Solid lines show spectral density of longitudinal (black) and vertical (red) velocity fluctuations. Vertical dashed lines mark wave numbers corresponding to stream width $\left(\kappa_{w}=1 / W\right)$, local water depth $\left(\kappa_{H}=1 / H\right)$ and measurement noise $\left(\kappa_{\text {noise }}=10 \mathrm{~Hz} / U_{\text {mean }}\right)$. The spectra are were calculated from unfiltered velocities. Note the different scales of spectral power in the three panels.

Mean dissipation rates of TKE estimated from inertial subrange fitting varied between $10^{-4} \mathrm{~W}$ $\mathrm{kg}^{-1}$ (SBT) and $10^{-2} \mathrm{~W} \mathrm{~kg}^{-1}$ (USW) (suppl. Table S2). The values increased with increasing flow speed, roughly following a power-law relationship $\varepsilon \sim \bar{u}^{3}$ (Fig. 4a). Dissipation rates obtained from power spectra of vertical velocity fluctuations $\left(\varepsilon_{w}\right)$ were consistently smaller than those from longitudinal velocity spectra $\left(\varepsilon_{u}\right)$. The anisotropy ratio $\left(\varepsilon_{u} / \varepsilon_{w}\right)$ increased with increasing flow velocities and dissipation rates from 1.2 in SBT and RIP flows, up to 7 at USW sites. The dissipation rates $\varepsilon_{w}$ and $\varepsilon_{u}$ measured at sampling spots within the same section were in the range between the two different section-scale dissipation estimates from bulk parameters $\varepsilon_{S}$ (Eq. 4) and $\varepsilon_{D}$ (Eq. 3).

Except for spot USW 2, velocity magnitude and turbulence properties, including TKE, rootmean-square velocity fluctuations and dissipation rates, did not show pronounced vertical structure (Fig. 4b). Spot USW 2, where the local flow depth was rather shallow (i.e., the bottom of PIV vector field corresponded to the bottom of the gravel riverbed), was characterized by a strong shear layer where the mean flow speed below $0.1 \mathrm{~m}$ depth rapidly decreased to near zero. 
a)

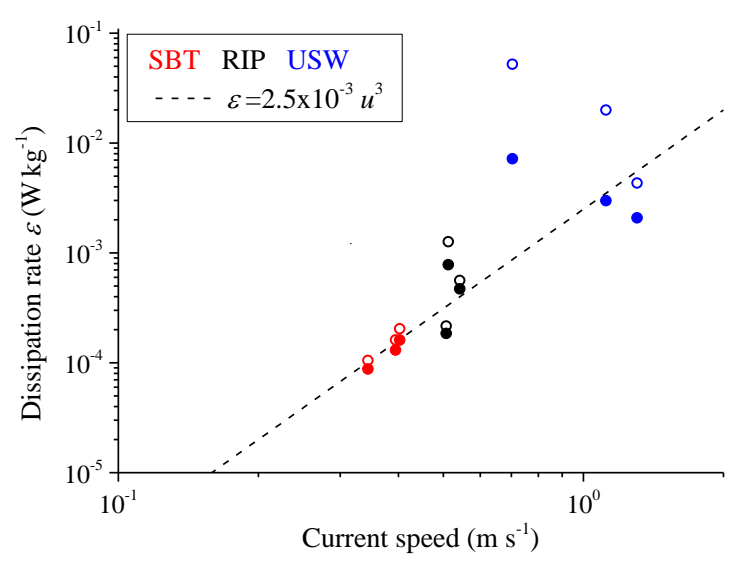

b)

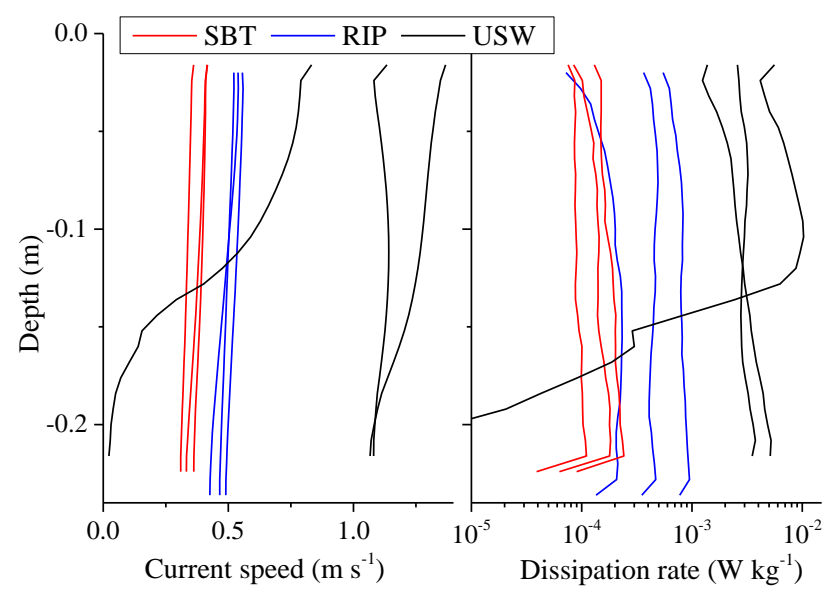

Figure 4: a) Dissipation rates of turbulent kinetic energy versus mean flow velocity for different surface flow types (symbol color, see legend). Filled symbols show dissipation estimates from vertical velocity fluctuations $\left(\varepsilon_{w}\right)$, open symbols are corresponding estimates from the longitudinal velocity component $\left(\varepsilon_{u}\right)$. The dashed line indicates a power law relationship between current speed and dissipation rates $\varepsilon_{w}$. b) Vertical profiles of temporarily and longitudinally averaged current speed and dissipation rates $\left(\varepsilon_{w}\right)$ with colors denoting different surface flow types (see legend).

\subsection{Drifter accelerations}

As expected for Lagrangian experiments, the drifter runs along a particular stream section followed different pathways. Mean travel times ( \pm standard deviation) were $40.0 \pm 9.6 \mathrm{~s}$ at SBT, $35.2 \pm 15.6 \mathrm{~s}$ at RIP, and $14.4 \pm 0.9 \mathrm{~s}$ at USW. Sequences, where the drifter passed the BSW (i.e., the hydraulic jump from drifter immerging until leaving the broken standing wave) were shorter (5.1 $\pm 1.6 \mathrm{~s})$. Examples of individual measured acceleration time series (Fig. 5a) show that drifter acceleration variance was similar between repeated runs at the same surface flow type, but mostly different among them, smoothest at SBT and with largest amplitudes at USW and BSW.

Although the drifter took different pathways, hence passed different subregions (e.g., more calm and slow, or more turbulent and wavy) of the sections, the total of measured acceleration time series of the sections can clearly be distinguished from each other. Individual runs at the SBT, where the drifter passes more rough subregions, could cause a standard deviations of accelerations larger than that measured by a drifter passing more smooth subregions at RIP (Fig 6b). The statistics in terms of mean and quantile of standard deviations of drifter accelerations obtained from multiple runs, however, enable to distinguish even such more similar surface flow types. The difference between these and that of the more wavy and turbulent flows in USW and BSW was one order of magnitude. 
a)

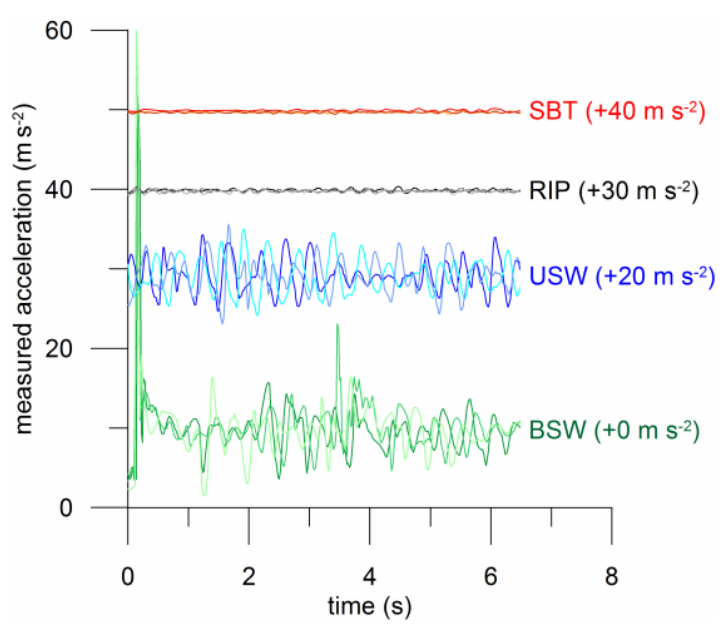

b)

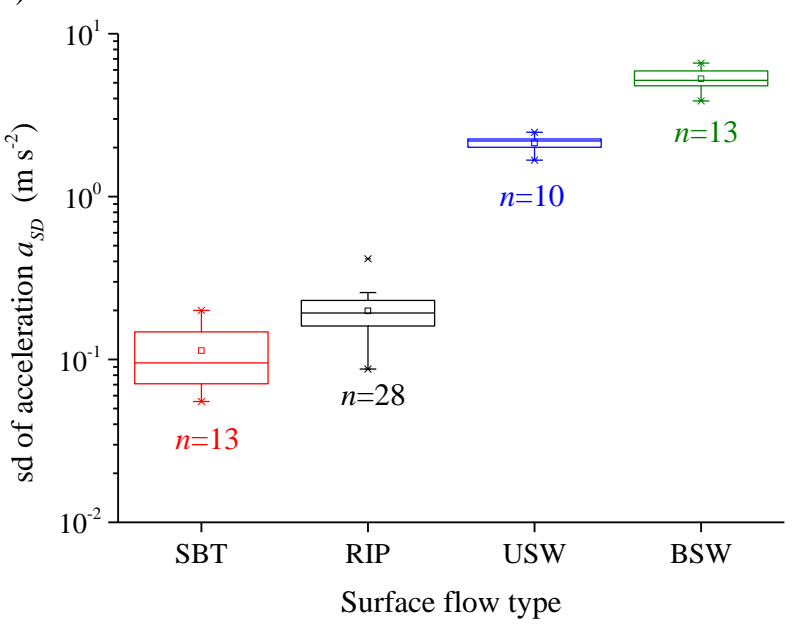

Figure 5: a) Examples of measured acceleration time series (6.5 s sequences) of three runs at each of the investigated surface flow types. The time series measured at the SBT, RIP and USW sections were plotted with vertical offset (values provided in parentheses) for clarity of the visualization. The characteristic peaks at the beginning of BSW time series correspond to the sudden and strong momentum the drifter gained while entering the hydraulic jump. $b$ ) Box plot of the standard deviations (sd) of instantaneous drifter acceleration $\left(a_{S D}\right)$ estimated for individual runs at stream sections with different surface flow type (SBT, RIP, USW and BSW). The boxes encompass the 25-75 percentile range, whiskers show minimum and maximum, and open squares and horizontal lines mark mean and median values, respectively. The number of drifter runs $(n)$ for each flow type is provided as labels.

\subsection{Gas exchange velocity as a function turbulence and surface flow type}

Generally, gas exchange velocities for both gases were increasing from SBT to RIP, USW and BSW (Fig. 6a, dissolved gas concentrations, fluxes and exchange velocities are listed in supplementary information, Table S2). While slightly overlapping ranges of variability were observed at SBT, RIP and USW sites, $k_{600}$ was generally larger at the BSW sites. Furthermore, $k_{600}$ estimated from $\mathrm{CH}_{4}$ fluxes was consistently higher compared to $k_{600}$ estimated for $\mathrm{CO}_{2}$, except at the BSW section (Fig. $6 \mathrm{~b}$ ). The ratio of $k_{600} \mathrm{CH}_{4} / k_{600} \mathrm{CO} 2$ was on average 1.3 at the SBT, RIP and USW sampling sites. The ratio $k_{600} \mathrm{CH}_{4} / k_{600} \mathrm{CO} 2$ did not depend neither on $p \mathrm{CH}_{4}$ nor on dissipation rate. 
a)

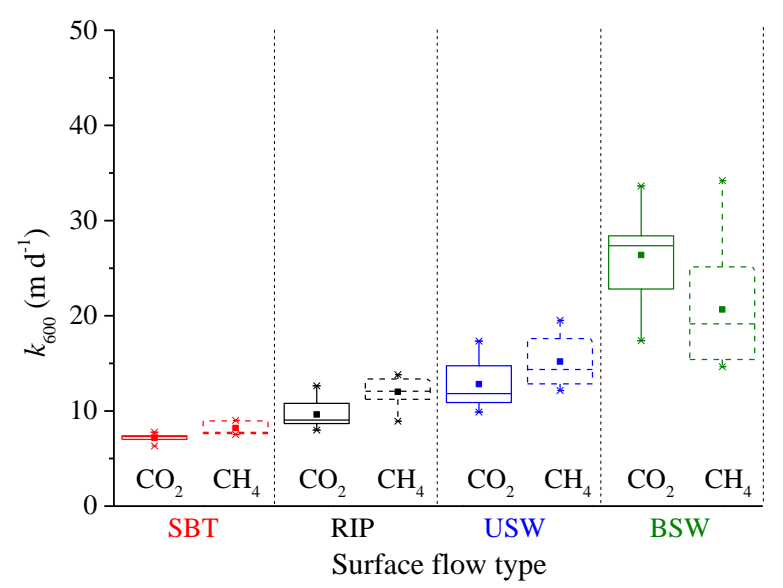

b)

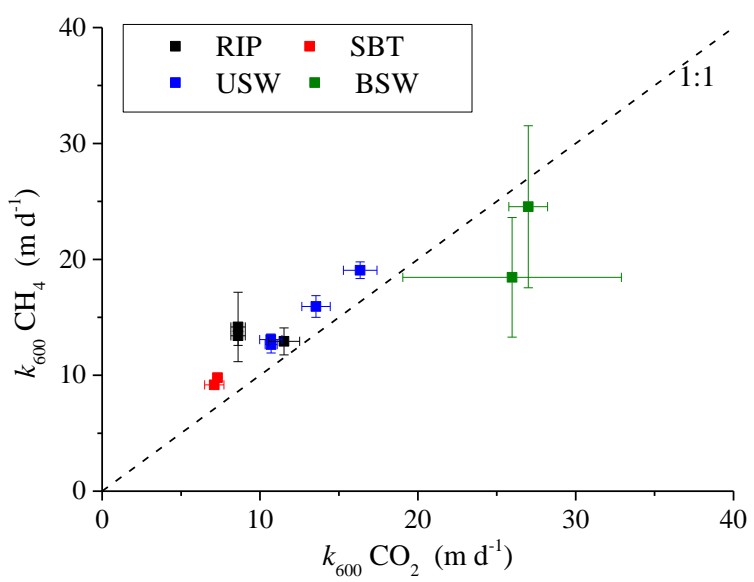

Figure 6: a) Box plot of gas exchange velocities for $\mathrm{CO}_{2}$ (solid lines) and $\mathrm{CH}_{4}$ (dashed lines) for different surface flow types. The boxes encompass the 25-75 percentile range, whiskers show minimum and maximum, and squaresymbols and horizontal lines mark mean and median values, respectively. b) Normalized gas exchange velocities $k_{600}$ estimated from measured $\mathrm{CH}_{4}$ fluxes versus $k_{600}$ estimated from $\mathrm{CO}_{2}$. Error bars indicate standard deviations of repeated flux measurements at each sampling spot.

The dependence of $k_{600}$ on dissipation rates followed the small eddy-model with a $\varepsilon^{1 / 4}$ powerlaw described by Katul and Liu (2017) (Eq. 1; Fig. 7). In comparison to former studies, the observed scaling factor $\alpha$ in Eq. 1 was at the upper end of reported values and was most closely related to those found by Zappa et al. (2007) for the coastal ocean and large rivers and by Vachon et al. (2010) for lakes and reservoirs. The scaling factor reported for laboratory channel flows by Moog and Jirka (1999b) underestimated gas exchange velocity by a factor of two. At the two USW sites with high flow speeds ( $>1 \mathrm{~m} \mathrm{~s}^{-1}$ ), deviations of dissipation-based estimates of $k_{600}$ from the small eddymodel with a constant scaling factor were largest for dissipation rates estimated from the longitudinal velocity component. More close correspondence, however, was observed for dissipation rates estimated from the vertical velocity component (Fig. 7a).

When applied to bulk estimates of turbulent dissipation rates estimated from channel geometry and mean flow velocity (Eq. 3 and 4), estimated gas transfer velocities and scaling coefficients $(\alpha)$ were in a similar range as those estimated from direct turbulence measurements (Fig. 7a). Due to the higher gas exchange velocities $k_{600}$ observed for $\mathrm{CH}_{4}$ in comparison to $\mathrm{CO}_{2}$, the corresponding scaling coefficients estimated from $\mathrm{CH}_{4}$ fluxes were generally higher. A summary of the mean scaling coefficients obtained from different combinations of dissipation rate estimates and measured gas exchange velocities is provided in supplementary information (Table S3). The average standard deviation of drifter acceleration at the different surface flow types was linearly related to gas exchange velocity for $k_{600}>7 \mathrm{~m} \mathrm{~d}^{-1}$ (Fig. 7b). 
a)

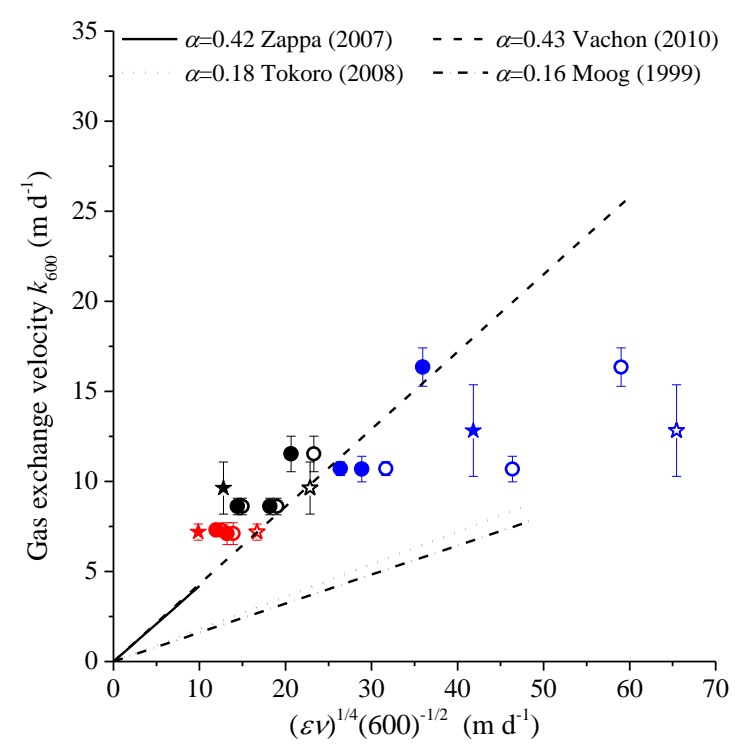

b)

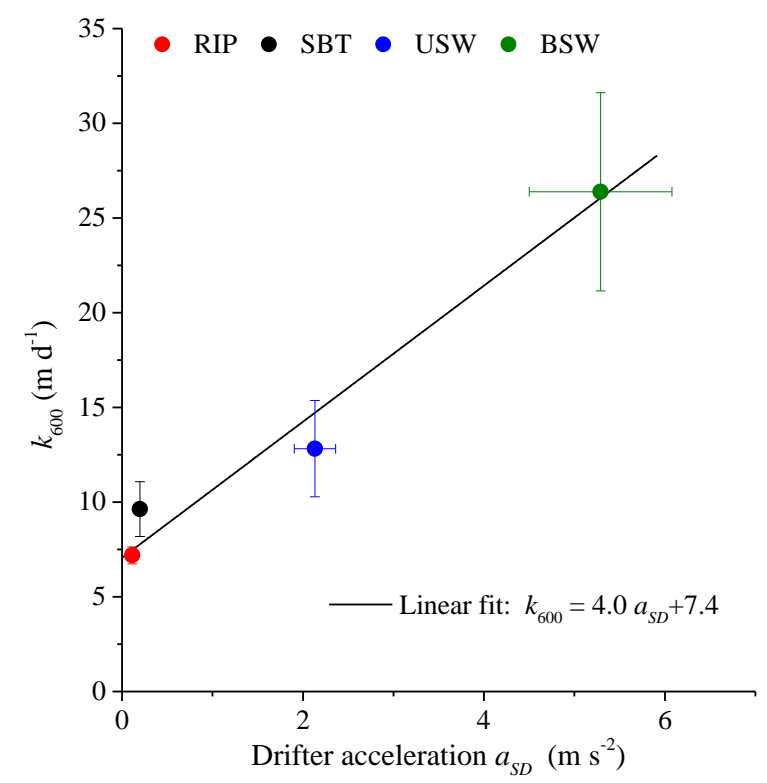

Figure 7: a) Dependence of normalized gas exchange velocities $k_{600}$ on dissipation rates (Eq. 1 with $S c=600$ ). Symbols show measured data $\left(k_{600}\right.$ from $\mathrm{CO}_{2}$, error bars indicate standard deviations from repeated chamber deployments) and dissipation rates estimated from the vertical ( $\varepsilon_{w}$, solid circular symbols) and longitudinal ( $\varepsilon_{u}$, open circular symbols) velocity components. Solid and open star-shaped symbols show corresponding estimates from section-scale dissipation rates $\left(\varepsilon_{S}\right.$ and $\varepsilon_{D}$, Table 1). Symbol colors indicate the different surface flow types (see legend in b). Lines show comparisons with other studies, which provided different estimates of the coefficient $\alpha$ in Eq. 1 (plotted for the respective data range covered by the original study). b) Observed gas exchange velocity $k_{600}$ (based on $\mathrm{CO}_{2}$ ) versus standard deviation of drifter acceleration for different surface flow types (see legend). The line shows a linear fit $\left(r^{2}=0.98, p=0.02\right.$, see legend for equation with slope and intercept). Horizontal and vertical error bars show standard deviations of different drifter runs and chamber deployments, respectively.

\section{Discussion}

\subsection{Gas exchange velocity and its relation to turbulence}

Here we demonstrated that the functional dependence of gas exchange velocity on turbulent energy dissipation rates follows the general scaling law derived from the small-eddy and surface divergence models (Eq. 1) under smooth and rippled flow conditions also in shallow streams. The empirical scaling coefficient $\alpha$ in this model was at the upper range, and slightly higher than corresponding coefficients derived for lakes and oceans (Fig. 7a). It appears promising that for these surface flow types, comparable agreement between measured and predicted gas exchange velocities was observed for section-scale dissipation estimates. Similar to drag-based parametrization of near-surface dissipation rates in terms of wind speed in wind-driven aquatic systems, mean dissipation rates in stream sections can be derived from the rate of change of potential energy of water flowing down a slope. As expected for smooth and small-roughness flows (Moog and Jirka 1999a), the dissipation rate estimates based on constant bed shear ( $\varepsilon_{S}$, Eq. 4) showed better agreement with locally measured dissipation rates for SBT and RIP flow types, while the drag-based approach $\left(\varepsilon_{D}\right.$, Eq. 3$)$ resulted in much higher dissipation rates. 
Turbulence was strongly anisotropic under rough flow conditions (unbroken stand wave) and, measured gas exchange velocities were lower than predicted from measured dissipation rates. However, in highly energetic and shallow USW flows, the assumption of isotropic turbulence and the presumed constancy of the coefficient $\alpha$ in Eq. 1 is not valid. Here we found better agreement between Eq. 1 and measured gas exchange velocities for dissipation estimates from the vertical velocity component. In a comparable study conducted in the coastal zone, Tokoro et al. (2008) excluded all measurements for which the ratio of dissipation rate estimates from different velocity components exceeded a factor of 6 . Application of this procedure to the present study would have resulted in no valid dissipation estimates for the USW flow type.

Except for the BSW flow type, gas exchange velocities estimated from fluxes of $\mathrm{CH}_{4}$ were systematically $30 \%$ higher than those estimated from $\mathrm{CO}_{2}$. Higher exchange velocities for $\mathrm{CH}_{4}$ has been explained by enhanced fluxes of less soluble gases due to microbubbles (Prairie and del Giorgio 2013; McGinnis et al. 2015). Microbubble enhancement can be expected to depend on surface flow type and greatest enhancement could be expected for BSW, where air entrainment by breaking waves is an explicit feature of the flow type definition. Although showing the largest variability among all flow types, the $\mathrm{CH}_{4}$ gas exchange velocities were comparable to those of $\mathrm{CO}_{2}$ at the BSW section (Fig. 6b). A $30 \%$ uncertainty in gas exchange velocity related to the type of gas is comparable in magnitude to corresponding uncertainties in $k_{600}$ obtained from dissipation rates (Eq. 1), which are typically associated with measurement errors of a factor of two (supplementary information). The much higher enhancement of $\mathrm{CH}_{4}$ fluxes observed in other studies (e.g., up to $250 \%$ in McGinnis et al., 2015 ) and the rather systematic nature of this uncertainty, however, call for a better understanding of the governing processes, including quantitative observations of microbubbles and the physical processes that control their generation and dynamics.

\subsection{Surface flow type mapping and larger-scale perspectives}

The results presented here provide first evidence that stream sections differing in surface flow type are characterized by different ranges of variability of near-surface turbulence and gas exchange velocities. The highest exchange velocities were observed for the BSW flow type, which were about four-fold those at the SBT site (Fig. 6). Although the range of variability in our study was small compared to more extensive surveys in small streams, where aeration coefficients (i.e. $k_{600}$ divided by flow depth) varied by more than two orders of magnitude across streams and stream reaches in a headwater system (Wallin et al. 2011; Schelker et al. 2016), our finding suggests that surface flow type categories could potentially provide a basis for constraining gas exchange velocities in streams. Surface flow types were introduced for a qualitative characterization of discrete hydraulic conditions within mesoscale units of the stream bed, described as physical biotopes (Newson and Newson 2000). Although it has been demonstrated that visual assessments of surface flow type distributions provide biologically relevant information, e.g. about spatial distributions of stream macroinvertebrates (Reid and Thoms 2008), their simple correlation to bed 
shear stress has been questioned because water depth is not explicitly taken into account (Clifford et al. 2006). However, surface flow types can be considered to characterize the hydraulic conditions at the water surface, as they are relevant for gas exchange at stream surfaces.

We found distinct ranges of acceleration variance along drifter runs for three different surface flow types and an empirical relationship between the standard deviation of drifter acceleration and gas exchange velocity. These first results suggest that the drifter can be a useful tool for both objective flow type mapping and section-scale assessments of gas exchange velocities in rough flows. Although the measured accelerations could not be mechanistically related to physical quantities of the flow, their variability can be considered as an empirical measure of surface roughness and near-surface turbulence and may facilitate a more objective and quantitative assessment of surface flow types than visual inspection. To what extent these relationships can be extended to include a wider range of flow types, and if they are consistent across streams differing in size and channel morphology, remain open questions, that need more data and further research. Future experiments relating gas exchange velocities to surface flow types and drifter applications should include reach-scale measurements of gas exchange velocities using tracer gas injection (Hornberger and Kelly 1975; Demars et al. 2015), since they provide exchange velocities at more relevant spatial scales.

A broader investigation of the relationship between flow type and gas exchange velocity appears to be a promising approach, because hydromorphological assessment has gained considerable attention in governmental monitoring, protection and restoration efforts. As one of the parameters for evaluating stream hydromorphology, European monitoring programs include mapping of 'flow features' and 'flow patterns' (Raven et al. 2002). Comprehensive monitoring programs of state authorities in Germany, for example, include mapping of 'flow diversity' as a qualitative assessment of the variability of surface flow types in streams and rivers at section-scale (LAWA 2000). Such maps can potentially provide a significant improvement of catchment-scale assessments of gas exchange velocities in streams. In addition to expanding the database for establishing a relationship between surface flow types and near-surface turbulence, further research is needed for potential up-scaling of such relationships to stream networks. Open research questions are related to the relevant spatial resolution at which surface flow type needs to be mapped, their superposition and stage dependence, as well as the accuracy and resolution of the mapping procedure.

\section{Acknowledgements}

We thank Christoph Bors for his help in preparing and conducting the measurements. This study was financially supported by the German Research Foundation (DFG, grant LO1150/9-1) and the Stiftung Rheinland-Pfalz für Innovation (Project 961-386261/1054). 


\section{Non-peer reviewed preprint submitted to EarthArXiv}

\section{References}

Alin, S. R., M. Rasera, C. I. Salimon, J. E. Richey, G. W. Holtgrieve, A. V. Krusche, and A. Snidvongs. 2011. Physical controls on carbon dioxide transfer velocity and flux in low-gradient river systems and implications for regional carbon budgets. J. Geophys. Res.-Biogeo. 116: G01009.

Alshboul, Z., J. Encinas-Fernández, H. Hofmann, and A. Lorke. 2016. Export of Dissolved Methane and Carbon Dioxide with Effluents from Municipal Wastewater Treatment Plants. Environ. Sci. Technol. 50: 5555-5563.

Aufdenkampe, A. K., E. Mayorga, P. A. Raymond, J. M. Melack, S. C. Doney, S. R. Alin, R. E. Aalto, and K. Yoo. 2011. Riverine coupling of biogeochemical cycles between land, oceans, and atmosphere. Front. Ecol. Environ. 9: 53-60.

Bluteau, C. E., N. L. Jones, and G. N. Ivey. 2011. Estimating turbulent kinetic energy dissipation using the inertial subrange method in environmental flows. Limnol. Oceanogr. Meth. 9: 302-321.

Bodmer, P., M. Heinz, M. Pusch, G. Singer, and K. Premke. 2016. Carbon dynamics and their link to dissolved organic matter quality across contrasting stream ecosystems. Sci Total Environ. 553: 574-586.

Clifford, N. J., O. P. Harmar, G. Harvey, and G. E. Petts. 2006. Physical habitat, eco-hydraulics and river design: a review and re-evaluation of some popular concepts and methods. Aquatic Conservation: Marine and Freshwater Ecosystems 16: 389-408.

Dahm, V. and others 2014. Strategien zur Optimierung von Fließgewässer-Renaturierungsmaßnahmen und ihrer Erfolgskontrolle, p. 174. Umweltbundesamt.

Demars, B. O. L., J. Thompson, and J. R. Manson. 2015. Stream metabolism and the open diel oxygen method: Principles, practice, and perspectives. Limnology and Oceanography: Methods 13: 356-374.

Emery, W. J., and R. E. Thomson. 2004. Data analysis methods in physical oceanography, 2nd ed. Elsevier.

Esters, L., S. Landwehr, G. Sutherland, T. G. Bell, K. H. Christensen, E. S. Saltzman, S. D. Miller, and B. Ward. 2017. Parameterizing air-sea gas transfer velocity with dissipation. J. Geophys. Res.-Oceans 122: 3041-3056.

Gålfalk, M., D. Bastviken, S. Fredriksson, and L. Arneborg. 2013. Determination of the piston velocity for water-air interfaces using flux chambers, acoustic Doppler velocimetry, and IR imaging of the water surface. J. Geophys. Res.-Biogeo. 118: 770-782.

Goldenfum, J. A. 2010. GHG Measurement Guidelines for Freshwater Reservoirs, p. 139 pp. UNESCO/IHA.

Goring, D., and V. Nikora. 2002. Despiking Acoustic Doppler Velocimeter Data. J. Hydraul. Eng. 128: 117-126.

Hornberger, G. M., and M. G. Kelly. 1975. Atmospheric reaeration in a river using productivity analysis. Journal of the Environmental Engineering Division 101: 729-739.

Hotchkiss, E. R., R. O. Hall Jr, R. A. Sponseller, D. Butman, J. Klaminder, H. Laudon, M. Rosvall, and J. Karlsson. 2015. Sources of and processes controlling $\mathrm{CO}_{2}$ emissions change with the size of streams and rivers. Nature Geosci. 8: 696-699.

Jähne, B., and H. Haußecker. 1998. Air-water gas exchange. Ann. Rev. Fluid Mech. 30: 443-468.

Jähne, B., K. O. Münnich, R. Bösinger, A. Dutzi, W. Huber, and P. Libner. 1987. On the parameters influencing airwater gas exchange. J. Geophys. Res. 92: 1937-1949.

Katul, G., and H. Liu. 2017. Multiple mechanisms generate a universal scaling with dissipation for the air-water gas transfer velocity. Geophys. Res. Lett.: n/a-n/a.

Kemp, J. L., D. M. Harper, and G. A. Crosa. 2000. The habitat-scale ecohydraulics of rivers. Ecol.Engin. 16: 17-29.

Lamont, J. C., and D. S. Scott. 1970. An eddy cell model of mass transfer into the surface of a turbulent liquid. AIChE Journal 16: 513-519.

LAWA. 2000. Länderarbeitsgemeinschaft Wasser, Empfehlungen-Oberirdische Gewässer: Gewässerstrukturgütekartierung in der Bundesrepublik Deutschland-Verfahren für kleine und mittelgroße Fließgewässer, 1. Aufl., Schwerin.

Long, H., L. Vihermaa, S. Waldron, T. Hoey, S. Quemin, and J. Newton. 2015. Hydraulics are a first-order control on CO2 efflux from fluvial systems. J. Geophys. Res.-Biogeo. 120: 1912-1922. 


\section{Non-peer reviewed preprint submitted to EarthArXiv}

Lorke, A. and others 2015. Technical note: drifting versus anchored flux chambers for measuring greenhouse gas emissions from running waters. Biogeosciences 12: 7013-7024.

Lorke, A., and F. Peeters. 2006. Toward a unified scaling relation for interfacial fluxes. J. Phys. Oceanogr. 36: 955961.

McGinnis, D. F., G. Kirillin, K. W. Tang, S. Flury, P. Bodmer, C. Engelhardt, P. Casper, and H.-P. Grossart. 2015. Enhancing Surface Methane Fluxes from an Oligotrophic Lake: Exploring the Microbubble Hypothesis. Environ. Sci. Technol. 49: 873-880.

Moog, D., and G. Jirka. 1999a. Stream Reaeration in Nonuniform Flow: Macroroughness Enhancement. J. Hydraul. Eng. 125: 11-16.

Moog, D. B., and G. H. Jirka. 1999b. Air-Water Gas Transfer in Uniform Channel Flow. J. Hydraul. Eng. 125: 3-10.

Mulholland, P. J. and others 2001. Inter-biome comparison of factors controlling stream metabolism. Freshwater Biol. 46: $1503-1517$.

Newson, M. D., and C. L. Newson. 2000. Geomorphology, ecology and river channel habitat: mesoscale approaches to basin-scale challenges. Progress in Physical Geography 24: 195-217.

Noss, C., P. Bodmer, K. Koca, and A. Lorke. 2018. Flow and Turbulence driven Water Surface Roughness and Gas Exchange Velocity in Streams. E3S Web Conf. 40: 05018.

Prairie, Y. T., and P. A. del Giorgio. 2013. A new pathway of freshwater methane emissions and the putative importance of microbubbles. Inland Waters 3: 311-320.

Raven, P. J., N. T. H. Holmes, P. Charrier, F. H. Dawson, M. Naura, and P. J. Boon. 2002. Towards a harmonized approach for hydromorphological assessment of rivers in Europe: a qualitative comparison of three survey methods. Aquatic Conservation: Marine and Freshwater Ecosystems 12: 405-424.

Raymond, P. A., C. J. Zappa, D. Butman, T. L. Bott, J. Potter, P. Mulholland, A. E. Laursen, W. H. McDowell, and D. Newbold. 2012. Scaling the gas transfer velocity and hydraulic geometry in streams and small rivers. Limnology \& Oceanography: Fluids \& Environments 2: 41-53.

Reid, M. A., and M. C. Thoms. 2008. Surface flow types, near-bed hydraulics and the distribution of stream macroinvertebrates. Biogeosciences 5: 1043-1055.

Rosentreter, J. A., D. T. Maher, D. T. Ho, M. Call, J. G. Barr, and B. D. Eyre. 2017. Spatial and temporal variability of $\mathrm{CO}_{2}$ and $\mathrm{CH}_{4}$ gas transfer velocities and quantification of the $\mathrm{CH}_{4}$ microbubble flux in mangrove dominated estuaries. Limnol. Oceanogr. 62: 561-578.

Schelker, J., G. A. Singer, A. J. Ulseth, S. Hengsberger, and T. J. Battin. 2016. $\mathrm{CO}_{2}$ evasion from a steep, high gradient stream network: importance of seasonal and diurnal variation in aquatic $p \mathrm{CO} 2$ and gas transfer. Limnol. Oceanogr. 61: 1826-1838.

Stamhuis, E. J. 2006. Basics and principles of particle image velocimetry (PIV) for mapping biogenic and biologically relevant flows. Aquatic Ecology 40: 463-479.

Tokoro, T., H. Kayanne, A. Watanabe, K. Nadaoka, H. Tamura, K. Nozaki, K. Kato, and A. Negishi. 2008. High gastransfer velocity in coastal regions with high energy-dissipation rates. J. Geophys. Res.-Oceans 113: C11006.

Vachon, D., Y. T. Prairie, and J. J. Cole. 2010. The relationship between near-surface turbulence and gas transfer velocity in freshwater systems and its implications for floating chamber measurements of gas exchange. Limnol. Oceanogr. 55: 1723-1732.

Wallin, M. B., M. G. Oquist, I. Buffam, M. F. Billett, J. Nisell, and K. H. Bishop. 2011. Spatiotemporal variability of the gas transfer coefficient $\left(K\left(\mathrm{CO}_{2}\right)\right)$ in boreal streams: Implications for large scale estimates of $\mathrm{CO}_{2}$ evasion. Global Biogeochem. Cycles 25: Gb3025.

Wang, B., Q. Liao, J. H. Fillingham, and H. A. Bootsma. 2015. On the coefficients of small eddy and surface divergence models for the air-water gas transfer velocity. J. Geophys. Res.-Oceans 120: 2129-2146.

Wanninkhof, R. 1992. Relationship between wind speed and gas exchange over the ocean. J. Geophys. Res. 97: 73737382.

Zappa, C. J., W. R. McGillis, P. A. Raymond, J. B. Edson, E. J. Hintsa, H. J. Zemmelink, J. W. H. Dacey, and D. T. Ho. 2007. Environmental turbulent mixing controls on air-water gas exchange in marine and aquatic systems. Geophys. Res. Lett. 34: L10601. 


\section{Supplemental material}

\subsection{Figure $S 1$}

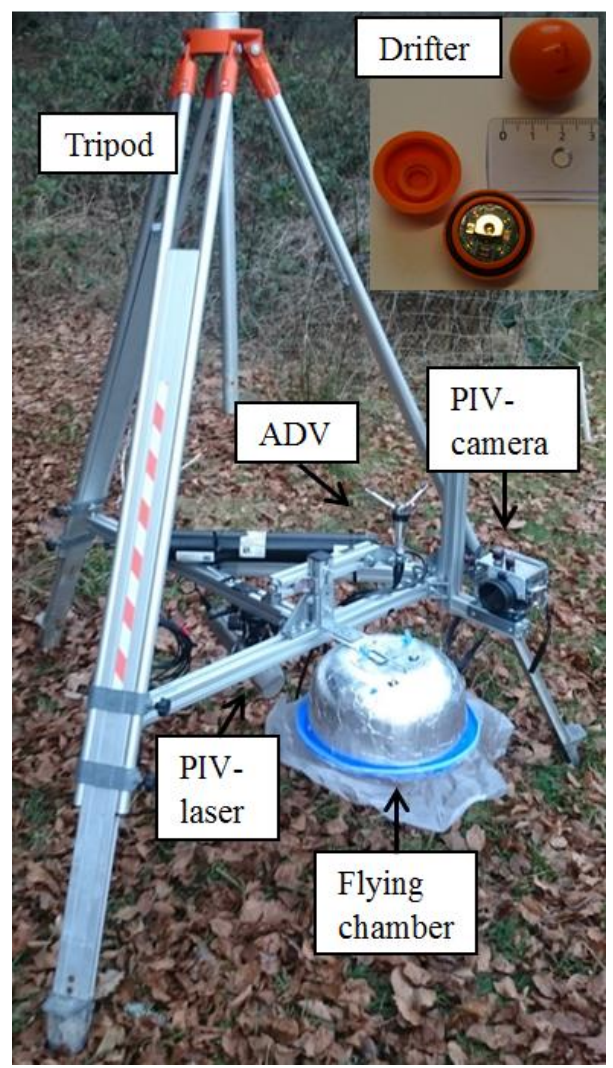

Figure S1: Measurement tripod instrumented with flying chamber, acoustic Doppler velocimeter (ADV) and particle image velocimeter (PIV). Note that ADV-sensor and PIV-camera are fixed at transport-positions and were lowered down and submerged for measuring flow and turbulence below the chamber. PIV-laser is slid to the back of the tripod during ADV-sampling. Inset picture shows the size of the spherical housing and electronics of the drifter. 


\section{Non-peer reviewed preprint submitted to EarthArXiv}

\section{$6.2 \quad$ Table $S 1$}

Table S1: Temporarily and spatially averaged flow properties at the measurement spots in stream sections with different surface flow types (SBT, RIP, USW): Flow speed $U_{\text {mean }}$ and turbulent kinetic energy TKE, root-meansquare $(\mathrm{rms})$ velocity fluctuations of longitudinal $\left(u_{r m s}\right)$ and vertical $\left(w_{r m s}\right)$ velocities and dissipation rates $\varepsilon$ estimated from inertial subrange fitting of longitudinal $\left(\varepsilon_{u}\right)$ and vertical $\left(\varepsilon_{w}\right)$ velocity fluctuations and the ratio of both dissipation rates (isotropy ratio).

\begin{tabular}{l|c|c|c|c|c|c|c} 
& $\begin{array}{c}U_{\text {mean }} \\
\left(\mathrm{m} \mathrm{s}^{-1}\right)\end{array}$ & $\begin{array}{c}\text { TKE } \\
\left(\mathrm{J} \mathrm{kg}^{-1}\right)\end{array}$ & $\begin{array}{c}u_{r m s} \\
\left(\mathrm{~m} \mathrm{~s}^{-1}\right)\end{array}$ & $\begin{array}{c}w_{r m s} \\
\left(\mathrm{~m} \mathrm{~s}^{-1}\right)\end{array}$ & $\begin{array}{c}\varepsilon_{u} \\
\left(\mathrm{~W} \mathrm{~kg}^{-1}\right)\end{array}$ & $\begin{array}{c}\varepsilon_{w} \\
\left(\mathrm{~W} \mathrm{~kg}^{-1}\right)\end{array}$ & $\begin{array}{c}\varepsilon_{u} / \varepsilon_{w} \\
(-)\end{array}$ \\
\hline SBT 1 & 0.39 & $1.7 \cdot 10^{-3}$ & 0.04 & 0.03 & $1.6 \cdot 10^{-4}$ & $1.3 \cdot 10^{-4}$ & 1.2 \\
SBT 2 & 0.34 & $1.4 \cdot 10^{-3}$ & 0.04 & 0.02 & $1.1 \cdot 10^{-4}$ & $8.8 \cdot 10^{-5}$ & 1.2 \\
SBT 3 & 0.40 & $2.3 \cdot 10^{-3}$ & 0.05 & 0.03 & $2.0 \cdot 10^{-4}$ & $1.6 \cdot 10^{-4}$ & 1.6 \\
\hline RIP 1 & 0.51 & $2.2 \cdot 10^{-3}$ & 0.05 & 0.03 & $2.2 \cdot 10^{-4}$ & $1.8 \cdot 10^{-4}$ & 1.2 \\
RIP 2 & 0.54 & $5.3 \cdot 10^{-3}$ & 0.07 & 0.05 & $5.6 \cdot 10^{-4}$ & $4.7 \cdot 10^{-4}$ & 1.2 \\
RIP 3 & 0.51 & $8.1 \cdot 10^{-3}$ & 0.10 & 0.06 & $1.3 \cdot 10^{-3}$ & $7.8 \cdot 10^{-4}$ & 1.3 \\
\hline USW 2 & 0.70 & $2.1 \cdot 10^{-2}$ & 0.17 & 0.08 & $5.2 \cdot 10^{-2}$ & $7.2 \cdot 10^{-3}$ & 7.2 \\
USW 3 & 1.12 & $2.4 \cdot 10^{-2}$ & 0.18 & 0.08 & $2.0 \cdot 10^{-2}$ & $3.0 \cdot 10^{-3}$ & 6.7 \\
USW 4 & 1.30 & $1.0 \cdot 10^{-2}$ & 0.11 & 0.07 & $4.3 \cdot 10^{-3}$ & $2.1 \cdot 10^{-3}$ & 2.1
\end{tabular}




\subsection{Table $S 2$}

Table S2: Dissolved gas concentrations and fluxes. Average \pm standard deviation of each surface flow type (bold) and spot for $\mathrm{CO}_{2}$ and $\mathrm{CH}_{4}$ partial pressure $(p)$, flux and gas exchange velocity $k_{600}$. Surface flow types are smooth boundary turbulence (SBT, rippled flow (RIP, unbroken standing wave (USW) and broken standing wave (BSW). $p \mathrm{CO} 2$ and $p \mathrm{CH} 4$ at the individual spots were estimated from only three replicated samples, hence no standard deviation is provided.

\begin{tabular}{|c|c|c|c|c|c|c|c|}
\hline $\begin{array}{l}\text { Surface } \\
\text { flow } \\
\text { type }\end{array}$ & Spot & $\begin{array}{c}\text { Water } p \mathrm{CO}_{2} \\
(\mathrm{ppm})\end{array}$ & $\begin{array}{c}\text { Flux } \mathrm{CO}_{2} \\
\left(\mathrm{mmol} \mathrm{m}{ }^{-2} \mathrm{~d}^{-1}\right)\end{array}$ & $\begin{array}{c}k_{600} \mathrm{CO}_{2} \\
\left(\mathrm{~m} \mathrm{~d}^{-1}\right)\end{array}$ & $\begin{array}{l}\text { Water } \\
p \mathrm{CH}_{4} \\
(\mathrm{ppm})\end{array}$ & $\begin{array}{c}\text { Flux } \mathrm{CH}_{4} \\
\left(\mathrm{mmol} \mathrm{m}{ }^{-2} \mathrm{~d}^{-1}\right)\end{array}$ & $\begin{array}{c}k_{600} \mathrm{CH}_{4} \\
\left(\mathrm{~m} \mathrm{~d}^{-1}\right)\end{array}$ \\
\hline \multirow[t]{3}{*}{ SBT } & All & $817.2 \pm 9$ & $98.44 \pm 7.18$ & $7.19 \pm 0.45$ & $78.5 \pm 2.6$ & $0.91 \pm 0.05$ & $8.21 \pm 0.7$ \\
\hline & SBT1 & 810 & $95.07 \pm 8.16$ & $7.1 \pm 0.61$ & 80.5 & $0.87 \pm 0.01$ & $7.66 \pm 0.11$ \\
\hline & SBT2 & 826.8 & $102.93 \pm 1.45$ & $7.31 \pm 0.1$ & 75.7 & $0.96 \pm 0.01$ & $8.96 \pm 0.05$ \\
\hline \multirow[t]{4}{*}{ RIP } & All & $810.6 \pm 5.1$ & $127.61 \pm 20.6$ & $9.63 \pm 1.44$ & $56.7 \pm 0.1$ & $0.96 \pm 0.12$ & $12.01 \pm 1.5$ \\
\hline & RIP1 & 804.7 & $111.68 \pm 5.91$ & $8.61 \pm 0.46$ & 56.8 & $0.92 \pm 0.06$ & $11.53 \pm 0.71$ \\
\hline & RIP2 & 814.6 & $121.89 \pm 6.1$ & $9.11 \pm 0.46$ & 56.6 & $0.93 \pm 0.2$ & $11.75 \pm 2.49$ \\
\hline & RIP3 & $814.6^{*}$ & $154.56 \pm 13.18$ & $11.53 \pm 0.98$ & $56.6^{*}$ & $1.03 \pm 0.09$ & $12.92 \pm 1.17$ \\
\hline \multirow[t]{5}{*}{ USW } & All & $886.8 \pm 33.8$ & $212.61 \pm 42.85$ & $12.82 \pm 2.54$ & $62.5 \pm 0.7$ & $1.34 \pm 0.25$ & $15.18 \pm 2.76$ \\
\hline & USW1 & 831.3 & $194.35 \pm 12.93$ & $13.55 \pm 0.9$ & 61.4 & $1.38 \pm 0.08$ & $15.93 \pm 0.94$ \\
\hline & USW2 & 899.8 & $280.97 \pm 18.28$ & $16.35 \pm 1.06$ & 63.1 & $1.7 \pm 0.06$ & $19.06 \pm 0.72$ \\
\hline & USW3 & 904.7 & $185.91 \pm 12.32$ & $10.69 \pm 0.71$ & 62.5 & $1.15 \pm 0.04$ & $13.08 \pm 0.47$ \\
\hline & USW4 & 911.4 & $189.21 \pm 6.73$ & $10.71 \pm 0.38$ & 63.2 & $1.13 \pm 0.07$ & $12.65 \pm 0.73$ \\
\hline \multirow[t]{3}{*}{ BSW } & All & $741.8 \pm 1.4$ & $274.86 \pm 54.48$ & $26.38 \pm 5.23$ & $49.5 \pm 0.2$ & $1.43 \pm 0.43$ & $20.66 \pm 6.33$ \\
\hline & BSW1 & 743.5 & $283.1 \pm 12.84$ & $26.99 \pm 1.22$ & 49.2 & $1.69 \pm 0.48$ & $24.54 \pm 6.99$ \\
\hline & BSW2 & 740.7 & $269.36 \pm 71.78$ & $25.97 \pm 6.92$ & 49.6 & $1.28 \pm 0.36$ & $18.45 \pm 5.16$ \\
\hline
\end{tabular}

*RIP3: for $p \mathrm{CO} 2$ and $p \mathrm{CH} 4$ we used the same partial pressure as measured in RIP2 (technical problem, measurements of RIP2 and RIP3 were measured within ca. 2 hours)

\section{$6.4 \quad$ Table $S 3$}

Table S3: Average scaling coefficient $\alpha$ in the small eddy-model (Eq. 1) for dissipation rates estimated from measured vertical $\left(\boldsymbol{\varepsilon}_{w}\right)$ and longitudinal $\left(\boldsymbol{\varepsilon}_{u}\right)$, velocity fluctuations (spot scale) and for section-scale dissipation rates estimated from bulk flow characteristics ( $\varepsilon_{s}$, Eq. 4 and $\varepsilon_{D}$, Eq. 3). All coefficients were estimated from measured gas exchange velocities $k_{600}$ from $\mathrm{CO}_{2}$ and for $\mathrm{CH}_{4}$ and represent mean values and standard deviations of all measurements from the SBT, RIP and USW sites.

Spot-scale
\begin{tabular}{l|l|l|l|l|l|l|l}
\multicolumn{2}{l|}{ Section-scale } \\
\hline$\alpha\left(\mathrm{CO}_{2}, \varepsilon_{w}\right)$ & $\alpha\left(\mathrm{CH}_{4}, \varepsilon_{w}\right)$ & $\alpha\left(\mathrm{CO}_{2}, \varepsilon_{u}\right)$ & $\alpha\left(\mathrm{CH}_{4}, \varepsilon_{u}\right)$ & $\alpha\left(\mathrm{CO}_{2}, \varepsilon_{D}\right)$ & $\alpha\left(\mathrm{CH}_{4}, \varepsilon_{D}\right)$ & $\alpha\left(\mathrm{CO}_{2}, \varepsilon_{S}\right)$ & $\alpha\left(\mathrm{CH}_{4}, \varepsilon_{S}\right)$ \\
\hline $0.53 \pm 0.09$ & $0.69 \pm 0.14$ & $0.46 \pm 0.15$ & $0.60 \pm 0.21$ & $0.37 \pm 0.14$ & $0.47 \pm 0.18$ & $0.63 \pm 0.27$ & $0.81 \pm 0.35$
\end{tabular}




\subsection{PIV-ADV comparison}

For the comparison of the ADV and PIV velocity measurements, we considered the longitudinal and vertical velocity components, which were measured subsequently by both instruments at the study sites. We compared the mean velocity magnitude, turbulence characteristics and power spectra from a single PIV interrogation area located within the ADV sampling volume (23 cm from the left and $12 \mathrm{~cm}$ from the top of the field of view).

Except for the measurements at USW spot 2, the mean velocity magnitudes were strongly correlated (Fig. S2a), although the mean current speeds measured by the PIV were on average $8 \%$ greater than those measured by the ADV. At USW spot 2, the PIV velocity was $>35 \%$ smaller than the ADV velocity, which we attribute to the potential instationarity of the strong shear layer that was observed at this site (cf. Fig. 5b). The observed differences between root-mean-square (rms) velocity fluctuations were larger $\left(+23 \%\right.$ for $u_{r m s}$ and $-9 \%$ for $w_{r m s}$ relative to ADV velocity, Fig. S2b). Largest differences between both instruments were observed for the USW measurements, where the strong noise in the vertical ADV velocity component (see below) can be expected to have caused the observed overestimation. At the SBT and RIP sites, the rms fluctuations measured by both instruments agreed better for the vertical velocity components, while that $u_{r m s}$ was consistently about $20 \%$ larger in the PIV than in the ADV measurements.
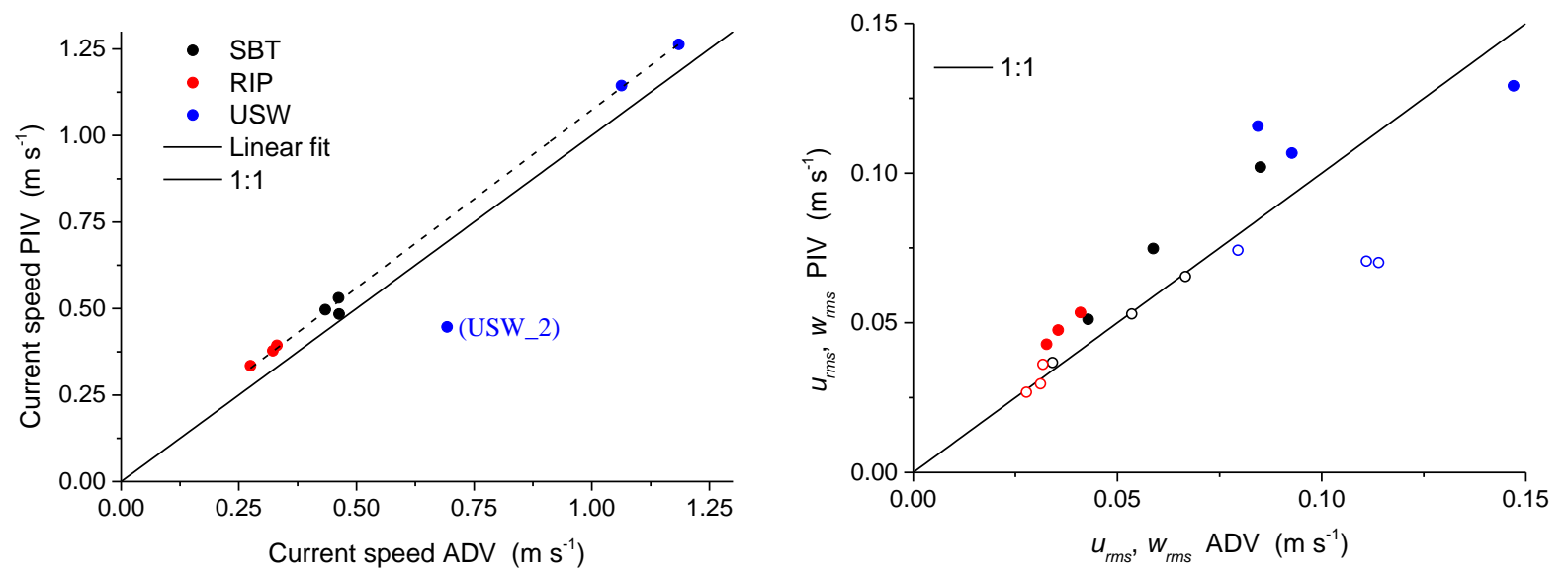

Figure S2: Comparison of a) mean flow speed $\left(\sqrt{\overline{u^{2}}+\overline{w^{2}}}\right.$ and b) root-mean-square velocity fluctuations $\left(u_{r m s}=\right.$ $\sqrt{\overline{u^{\prime 2}}}$, filled symbols and $w_{r m s}=\sqrt{\overline{w^{\prime 2}}}$, open symbols) estimated from ADV and PIV measurements. The PIV data represent the temporal mean of a single interrogation area at the location of the ADV sampling volume. Different colors denote different surface flow types (see legend). The dashed line in a) shows the result of a linear regression (excluding the measurements at USW_2): $u_{P I V}=1.03 * u_{A D V}+0.04 \mathrm{~m} \mathrm{~s}^{-1}, r^{2}=0.99$. The same symbol color assignment as in a) was used in b).

The spectral distribution of velocity variance measured by both instruments agreed in many aspects, inclduing the inertial subrange. Measurement noise, i.e. a flat spectrum with constant power spectral density at high frequencies, varied among instruments, among deployments and, in the case of ADV, also among velocity components (Fig. S3). Particularly in the USW 
measurements, the spectra of the vertical ADV velocity component (which corresponded to the longitudinal velocity component in the more common upright deployment of the instrument) was strongly affected by noise. This noise significantly contributed to turbulent kinetic energy and rootmean-square velocity variance and was therefore removed prior to TKE estimation by low-pass filtering (see method section in main manuscript). In the PIV measurements, an equal noise level was observed for the longitudinal and vertical velocity components, which was slightly higher than the noise level of the longitudinal ADV velocity component.

a) SBT 2

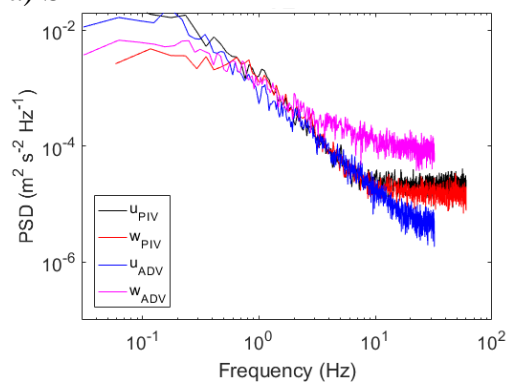

b) RIP 1

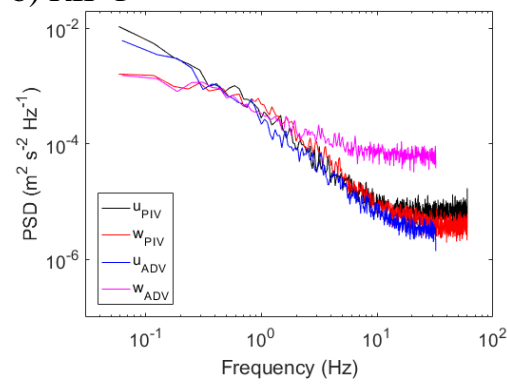

c) USW 4

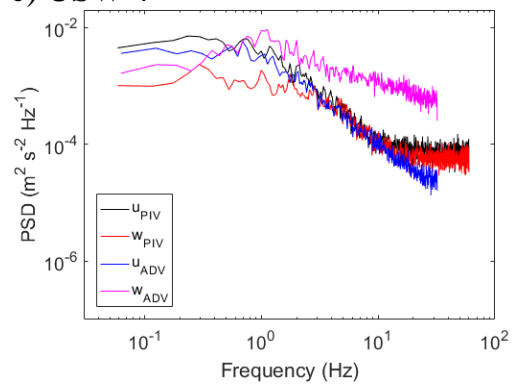

Figure S3: Comparison of power spectral density of longitudinal $(u)$ and vertical $(w)$ velocity fluctuations measured by PIV and ADV at three selected spots (a) SBT 2, b) RIP 1, c) USW 4. Note the identical axis scale in all panels, see legend for line color assignments.

Dissipation rates of turbulent kinetic energy obtained from inertial subrange fitting of velocity spectra agreed mostly within a factor of two among both instruments (Fig. S4). Larger differences were mainly observed for dissipation estimates from the vertical velocity spectra at the USW sites. The inertial subrange in these spectra was below the noise level of the vertical ADV velocity, while a clear inertial subrange was observed in the PIV measurements and for the longitudinal component for both instruments.

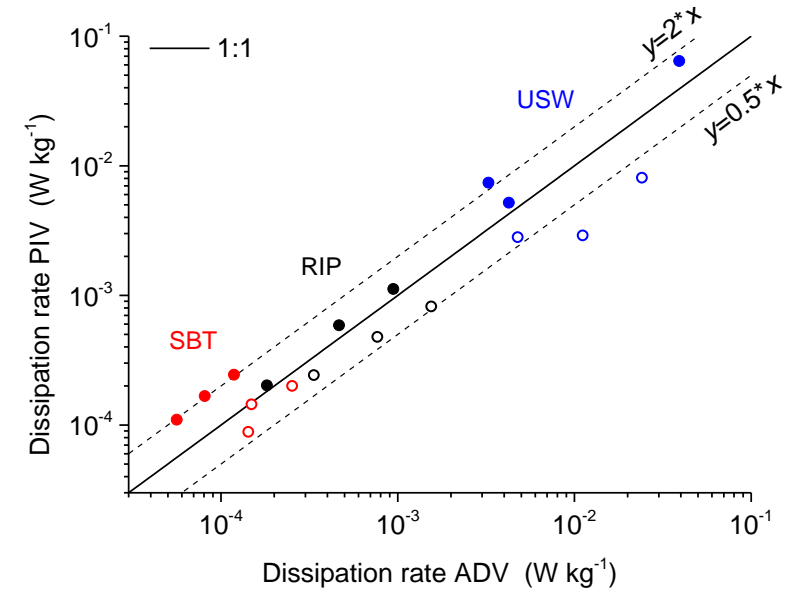

Figure S4: Comparison of dissipation estimated from inertial subrange fitting for ADV and PIV measurements. Open symbols represent dissipation rates estimated from the longitudinal velocity component $\left(\varepsilon_{u}\right)$ and filled symbols are based on vertical velocity fluctuations $\left(\varepsilon_{w}\right)$. The solid line represents a $1: 1$ relationship, dashed lines indicate uncertainty of a factor of two. 